\title{
Workshop_-Ground Truthing and Virtual Field Trips
}

\author{
Oliver Dawkins \\ Building City Dashboards \\ Maynooth University Social Sciences Institute \\ Maynooth University \\ Maynooth, Ireland \\ oliver.dawkins@mu.ie
}

\author{
Gareth W. Young \\ $V$-SENSE \\ School of Computer Science and Statistics \\ Trinity College Dublin \\ Dublin, Ireland \\ youngga@tcd.ie
}

\begin{abstract}
This workshop will provide iLRN 2020 delegates with an opportunity to extend their knowledge of shared immersive virtual environments (IVEs) in the context of teaching and learning through co-creation. The workshop will begin by outlining methods for capturing digital media in-situ, establishing the 'ground truth' of a place as both teaching preparation and as a learning activity in its own right. The workshop will then demonstrate how data captured in physical locations can be incorporated into online 3D models that can be experienced as a 'virtual field trip' in social virtual reality (VR). This activity highlights the student's constitutive role in the selection and capture of data representing their environment and encourages active learning through engagement with the creation of IVEs. Workshop participants will be taken on a virtual expedition into one such model to stimulate further discussion about how these environments can be used to promote active learning. While the session focuses on the use of captured media to establish the ground truth of a location, the session will also consider the further potential of social IVEs as opportunities for storytelling, repositories of shared experience, and as a means for imagining and experimenting with counter-factual histories and alternative futures.
\end{abstract}

Index Terms - virtual reality, co-creation, virtual field trip, location-specific media, virtual learning environments

\section{TARget Audience And ReQuirements}

This iLRN workshop is suitable for anyone with an interest in using consumer technologies such as smartphones to capture physical aspects of their environment, the "ground truth" of a geographic location [1], and use 3D authoring software to generate 3D models that can be assembled to create IVEs. The workshop will be of concern to educators and researchers who are interested in using open-source and free to use software to create unique IVEs that can be shared as virtual learning environments (VLEs) in social VR. The session will introduce generally applicable concepts, ideas, and approaches that are contextualized regarding a specific workflow developed in prior research [2]. We invite participants to join us on a virtual field trip of an environment constructed using that workflow. This IVE will serve as a backdrop for the delivery and discussion of materials intended to engage the active learning and participation of students through co-creation.

During the session, we will be sharing links to relevant tutorials for later use, and no coding experience is required. Furthermore, AltspaceVR provides a free desktop PC application (www.altvr.com) which can be used to participate without the use of a head-mounted display (HMD). To participate you will need the following:

Required -

- A Windows PC with internet access

- An AltspaceVR account

Desirable -

- A compatible HMD

\section{Novelty AND Timeliness}

Both public and private learning institutions are investing increasing time and effort in establishing online learning initiatives. At the same time, the software being developed for $3 \mathrm{D}$ authoring and social VR is advancing in both technical capabilities and accessibility to a broader audience of potential users and content creators. These tools and software packages take many forms and do not necessarily require advanced programming skills to achieve visually compelling results. "The field trip is the perfect metaphor for VR learning" [3, p. 190], therefore, many social VR platforms have facilitated user-generated projects that are designed to enhance the virtual learning environment (VLEs) with bespoke content. However, as the key participants and beneficiaries of emerging VLE platforms and new teaching practices, teachers and students may have had little involvement in their visioning, content selection, and operation. The practice we are developing seeks to encourage confidence in the use of 3D technologies through engagement with the process of content creation.

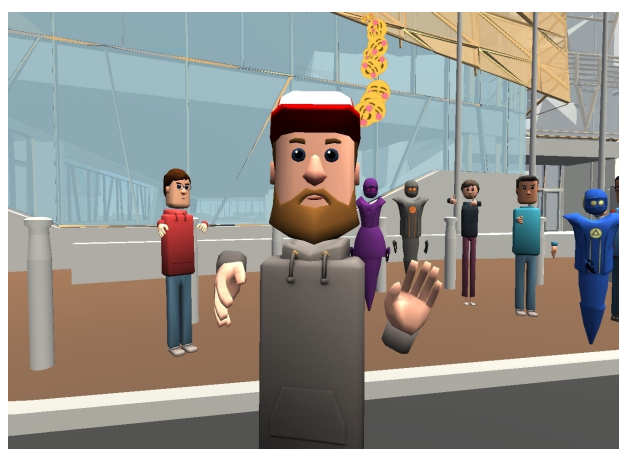

Fig. 1. Virtual Field Trip in Social VR. 


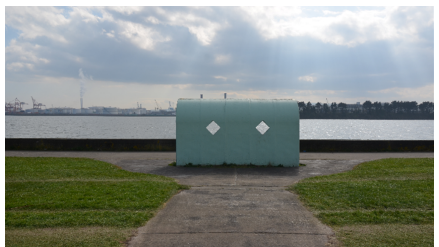

(a) In-situ Image and Audio Capture.

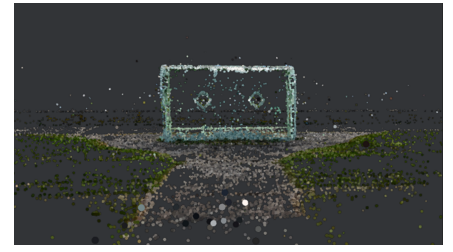

(b) Structure from Motion.

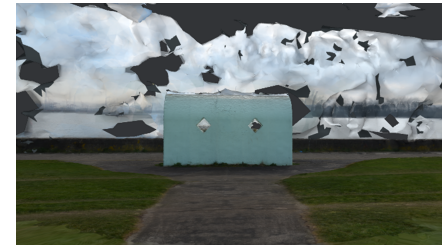

(c) Textured Model.

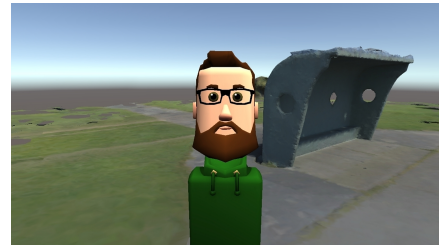

(d) Multimodal AltspaceVR Environment.

Fig. 2. Examples of data capture and processing from the workshop.

\section{WORKSHOP DESCRIPTION AND SESSION PLAN}

The workshop will involve a presentation followed by a virtual field trip into the Dublin Docklands, Ireland. This will take place in AltspaceVR and will last approximately 2-hours.

- Introductions - who we are; what we do; where we are meeting (the Dublin Docklands 3D model); why we are meeting in this virtual space

We will present on how this particular approach goes beyond consultation by building and deepening equal collaboration between students and teachers that are each impacted by remote-learning practices differently.

- Presentation - co-design will be discussed as a strategic approach to creating shared immersive learning environments and actively involving multiple stakeholders in the design process [2]

This will be elaborated alongside a high-level overview of the technical process for capturing data and constructing virtual environments using a Meshroom - Blender - Unity - AltspaceVR workflow. Materials outlining this process in more detail will be made available before the workshop. However, advanced reading is not required. These materials are provided to support participants who are interested in trying the workflow for themselves after the workshop. As proof of concept, a task will then be set to demonstrate the value of the $3 \mathrm{D}$ model.

- Exploration - workshop attendees will be set upon a learning task to further explore the map

The session will demonstrate the appeal of such tasks and activities for communicating the different ways in which 3D models can be created that maintain contextual and effective links to the places they represent.

- Wrap up - the group will then report back on their learning experiences, outcomes, and future ideas for virtual classroom integration

A 'show and tell' for delegates who may have complete similar workflows in advance will also be made available at this time (this will be time-dependent). This event was conceived to stimulate engagement and curiosity among members of the iLRN cohort towards the use of concepts of mixed reality, social VR software, and open-source software to engage students in the active co-creation and use of $3 \mathrm{D}$ data.

\section{OBJECTIVES AND TAKE-AwAys}

The goal of this workshop is to introduce attendees to practical solutions for the collection of place-based multimedia and $3 \mathrm{D}$ information that can be used in the construction of VLEs. The concepts of ground truth and the virtual field trip convey the different teaching and learning potentials offered through the separate activities of constructing and exploring virtual environments based on real-world locations. The workshop will actively involve the delegates of iLRN in a stimulating, hands-on activity with content and take-away materials that offers relevance and meaningful rewards for student engagement in VR.

The supplementary materials provided in advance of the session will demonstrate how student-teacher generated content can be incorporated into a 3D model and experienced as a virtual field trip. This highlights the added value to learning that could be gained through student participation in the preparatory and hands-on activity of data collection in the real world. Different means of observation, sensing, and measurement on location establish a sense of "ground truth" [1]. The Virtual Field Trip then provides opportunities to explore wider questions of context and meaning relating to a place and to reconsider their past, present, and future in engaging ways. Delivered using virtual reality such activities also have applications for remote learning contexts.

\section{WORKSHOP MATERIALS}

Further information and workshop materials will be available via the project website: https://virtualarchitectures.github. io/ground_truthing_and_virtual_field_trips/

\section{ACKNOWLEDGMENTS}

This workshop has been developed as part of research supported by the Maynooth University Social Sciences Institute's Early Career Researcher Awards Scheme 2019-2020 and the Science Foundation Ireland (SFI) - under the Investigators' Award Program for the Building City Dashboards Project at Maynooth University (15/IA/3090) and the V-SENSE Project at Trinity College Dublin (15/RP/2776).

\section{REFERENCES}

[1] J. Pickles, Ground truth: The social implications of geographic information systems. Guilford Press, 1995. 
[2] O. Dawkins and G. W. Young, "Engaging place with mixed realities: Sharing multisensory experiences of place through community-generated digital content and multimodal interaction." in Human Computer Interaction International, Copenhagen, 2020.

[3] J. Bailenson, Experience on demand: What virtual reality is, how it works, and what it can do. WW Norton \& Company, 2018. 